\title{
Prospective pilot study of fully covered self-expand- able metal stents for refractory benign pancreatic duct strictures: long-term outcomes
}

Authors

Institution
Saburo Matsubara, Naoki Sasahira, Hiroyuki Isayama, Naminatsu Takahara, Suguru Mizuno, Hirofumi Kogure, Natsuyo Yamamoto, Yousuke Nakai, Minoru Tada, Kazuhiko Koike

Graduate School of Medicine, The University of Tokyo - Gastroenterology, Tokyo, Japan submitted 25. January 2016 accepted after revision 1. August 2016

\section{Bibliography}

Dol http://dx.doi.org/ 10.1055/s-0042-115934 Published online: 10.11.2016 2016; 04: E1215-E1222

(c) Georg Thieme Verlag KG Stuttgart . New York E-ISSN 2196-9736

\section{Corresponding author:} Hiroyuki Isayama Graduate School of Medicine The University of Tokyo Gastroenterology

7-3-1 Hongo, Bunkyo-ku Tokyo 113-8655

Japan

Phone: +81-3-3815-5411 Fax: +81-3-5800-9801

isayama-tky@umin.ac.jp Endoscopy International Open

Background and study aims: Temporary placement of a fully covered self-expandable metal stent (FCSEMS) has recently emerged as a treatment option for pancreatic duct strictures due to chronic pancreatitis refractory to conventional plastic stenting. However, there are no data about long-term outcomes with this therapeutic option. The aims of the current study were to estimate the feasibility, safety, efficacy, and long-term outcomes of temporary FCSEMS placement for refractory pancreatic duct strictures.

Patients and methods: This was a prospective, single-center feasibility study. Ten patients with refractory pancreatic duct strictures due to chronic pancreatitis underwent FCSEMS placement for 3 months. We evaluated the rate of recurrent symptoms after stent removal during long-term follow-up, as well as adverse events (AEs).

Results: Two patients required early (within 1 week) stent removal because of intolerable pain or pancreatitis. In the remaining 8 patients, the recurrence rate of any symptoms after FCSEMS removal was $63 \%$ during 35 months of follow up.

\section{Introduction}

\section{$\nabla$}

Endoscopic placement of a single plastic stent (PS) to the main pancreatic duct (MPD) is a widely accepted treatment method for symptomatic strictures in patients with chronic pancreatitis $[1,2]$. Although adequate stent placement in the dominant stricture will relieve pain in the majority of patients [3-5], stents cannot be definitively removed in approximately one-third of patients because of persistent or recurrent strictures [6$9,10]$. In such refractory cases, placement of multiple PSs has been reported to be feasible and effective for obtaining enduring resolution of strictures and preventing pain [11].
With their large diameters, self-expandable metal stents (SEMS) have emerged as an option for the
The causes of recurrent symptoms were as follows: recurrence of stricture in 2; stent-induced stricture in 1 ; impaction of pancreatic stones in 1 ; and development of a pseudocyst in 1 . When limited to stricture, the recurrence rate was $38 \%$. Additional endoscopic treatments were required in 4 patients: a second FCSEMS placement in 1; plastic stent (PS) placement in 1; stone extraction in 1; and endoscopic ultrasound-guided pseudocyst drainage in 1 . Asymptomatic stent migration occurred in 2 patients. Suppurative pancreatic ductitis due to food impaction in the FCSEMS occurred in 2 patients, and endoscopic pancreatic duct drainage was performed. Stent-induced ductal changes developed in 2 patients and PS treatment was required in 1 patient for pain relief. Conclusion: The FCSEMS appears to be a feasible and potentially effective option for the management of refractory pancreatic duct strictures due to chronic pancreatitis during long-term followup. AEs including post-procedure pain, stent-induced ductal changes, migration, and ductitis are issues that need to be resolved.

durable resolution of refractory MPD strictures, as with the biliary tract [12]. However, uncovered SEMS placement must be discouraged for benign conditions because of the high dysfunction rate and the inability to remove the SEMS because of tissue hyperplasia through the wire mesh [13]. Tissue hyperplasia should be prevented by fully covered SEMS (FCSEMS). However, FCSEMS have been thought to be associated with risks of pancreatitis and pancreatic sepsis caused by occlusion of side branches of the pancreatic duct and stent migration. Contrary to these concerns, several pilot studies have recently shown favorable results with temporary FCSEMS placement for benign refractory pancreatic duct strictures without severe complications [14-19]. 
To date, temporary FCSEM placement is regarded as an alternative to multiple PSs for benign refractory pancreatic duct strictures due to chronic pancreatitis $[20,21]$. However, there are few data regarding short-term results of FCSEM placement, and no data regarding long-term outcomes of FCSEM application. The aim of this prospective study was to investigate the feasibility, safety, efficacy, and long-term outcomes after temporary placement of an FCSEM for refractory benign MPD strictures due to chronic pancreatitis.

\section{Patients and Methods}

\section{$\nabla$}

\section{Study design}

This study was designed as a prospective, single-arm, single-center, pilot study of feasibility. The study protocol was approved by the institutional review board of Tokyo University Hospital. The study was registered in the University Hospital Medical Information Network Clinical Trials Registry (UMIN000007549). The study was investigator-initiated and was conducted according to the ethical principles of the Declaration of Helsinki. Written informed consent was obtained from all patients.

\section{Patients}

We recruited consecutive patients with MPD strictures due to chronic pancreatitis refractory to conventional endoscopic treatment with a single PS. Annually, only a few patients were estimated to be acceptable for the study according to the criteria in our institute; therefore, 10 patients were scheduled to participate in this study. Inclusion criteria were as follows: (1) dominant stricture of the MPD in the pancreatic head or body; (2) recurrent pain or pancreatitis after PS removal caused by unresolved stricture or requirement for continuous PS placement for symptomatic unresolved stricture; (3) previous placement of a single PS with regular intervals of stent exchange for at least 3 months; and (4) age 20 years old or older. Exclusion criteria were as follows: (1) inaccessibility to the papilla with the duodenoscope; (2) poor general condition with severe comorbidities; (3) patient's refusal to participate in the study; (4) acute pancreatitis requiring hospitalization; or (5) unsuitable patient as judged by investigators. Brush cytology of the stricture was routinely performed prior to initial PS placement and malignancy was not detected in any case.

\section{Interventions}

All procedures of transpapillary FCSEMS deployment were performed with standard endoscopic retrograde cholangiopancreatography (ERCP). Patients were sedated with diazepam and pethidine hydrochloride while in the prone position. We used oblique-viewing therapeutic duodenoscopes (TJF260V or JF260V; Olympus Medical Systems, Tokyo, Japan). Pancreatography was performed after cannulation of the MPD, and the dominant stricture of the MPD was depicted. After traversing the stricture using a guidewire, an FCSEMS was inserted across the stricture, with the distal end of the FCSEMS placed in the duodenum. Pancreatic sphincterotomy was not performed. Balloon dilation of the stricture or papilla had been performed if needed at the time of stenting or stone extraction. FCSEMSs were Nit-S stents (Taewoong Medical, Seoul, Korea), including the D- type and the Bumpytype. The D-type stent, consisting of a nitinol wire and a polytetrafluoroethylene (PTFE) covering membrane, was designed for the optimal balance of radial force and conformability in the pancreatic duct. A previous study revealed the feasibility of the D-type stent, but migration was common [16]. The Bumpy-type stent had anti-migration features, with flared ends and an irregular cell size to obtain different segmental radial forces. The covering membrane materials were silicone at both ends to create an efficient flare, with PTFE at the middle portion to obtain high conformability [17]. FCSEMS were 6,8 , or $10 \mathrm{~mm}$ in diameter and $5,6,7,8,9$, or $10 \mathrm{~cm}$ in length. We chose the diameter of the FCSEMS according to the diameter of the MPD upstream of the stricture. The length of the FCSEMS depended on the location of the stricture and the ductal configuration. We selected longer stents for the following reasons: prevention of proximal and distal migration by full expansion of both stent ends [22]; and reduction of the risk of stent dysfunction or stent-induced ductal change due to MPD kinking [22]. The diameter of the FCSEMS introducer was $8.5 \mathrm{Fr}$. None of the FCSEMSs were approved by pharmaceutical affairs in Japan, so they were purchased directly from the company, and the cost was considered to be a research expense. The authors have no conflict of interest to declare.

\section{Follow-up}

Patients were followed-up every month after FCSEMS placement with abdominal X-ray and laboratory tests including pancreatic and liver enzymes, C-reactive protein, and complete blood cell counts. Three months after placement the FCSEMS were removed through an endoscope using snare forceps and pancreatography was performed immediately after removal. If there was no definite improvement in the stricture, then the FCSEMS was replaced with a new one for an additional 3 months. After removal of the FCSEMS, patients were examined for clinical and laboratory findings every month during the study period.

\section{Definition of events and study outcomes}

The primary outcome was symptom recurrence after removal of the FCSEMS. Recurrence of symptoms was defined as pain or pancreatitis. Secondary outcomes included technical success rate, total duration of FCSEMS placement, improvement rate of the stricture at the time of FCSEMS removal, recurrence-free survival after FCSEMS removal, early and late complications, and status of patients at the latest follow-up of the study period. Technical success was defined as accurate positioning of the stent so that it was covering the entire length of the stricture and crossed the papilla. Improvement of the stricture was defined as an increase in the diameter of the narrowest portion of the stricture, and an inflated extraction balloon could be passed through the pancreatic duct on follow-up pancreatography at the time of stent removal. The extraction balloon was the injection-above Extractor (Boston Scientific Corp, Natick, Mass), with balloon size $9 \mathrm{~mm}$ to $12 \mathrm{~mm}$. The balloon was inflated to the diameter of the MPD upstream of the stricture. Early complications were defined as procedure-related or stent-related adverse events within 7 days after placement of the FCSEMS. Late complications were defined as stent-related adverse events, with an indwelling FCSEMS, after the eighth day of FCSEMS placement.

\section{Statistical analysis}

Descriptive continuous variables were presented as medians and interquartile ranges. Pre-stenting and post-stenting diameters of the narrowest portion of the stricture were compared by using the two-sample Wilcoxon signed rank test. The Kaplan-Meier method was used to estimate recurrence-free survival after stent removal. Statistical analysis was performed using JMP Pro version 
Table 1 Patient characteristics.

\begin{tabular}{|c|c|c|c|c|c|c|c|c|}
\hline Case & Age & Gender & $\begin{array}{l}\text { Toxic or etiologic } \\
\text { factor of chronic } \\
\text { pancreatitis }\end{array}$ & $\begin{array}{l}\text { Duration from } \\
\text { initial placement } \\
\text { of PS (months) }\end{array}$ & $\begin{array}{l}\text { Number of } \\
\text { previous ERCPs }\end{array}$ & $\begin{array}{l}\text { Concomitant } \\
\text { biliary stent (F) }\end{array}$ & $\begin{array}{l}\text { Management of MPD } \\
\text { stones prior to FCSEMS } \\
\text { placement }\end{array}$ & $\begin{array}{l}\text { MPD diameter } \\
\text { downstream/ } \\
\text { upstream (mm) }\end{array}$ \\
\hline 1 & 53 & M & Alcohol & 80 & 25 & - & $E S W L+E R C P$ & $2.8 / 8.4$ \\
\hline 2 & 48 & M & Alcohol & 65 & 17 & 8.5 & $E S W L+E R C P$ & $3.2 / 11.9$ \\
\hline 3 & 36 & $\mathrm{~F}$ & Trauma & 6 & 5 & 8.5 & Absent of stone & $2.1 / 7.7$ \\
\hline 4 & 47 & M & Alcohol & 17 & 5 & 10 & Absent of stone & $1.6 / 9.4$ \\
\hline 5 & 58 & $\mathrm{~F}$ & Alcohol & 17 & 13 & 8.5 & $E S W L+E R C P$ & $1.4 / 7.7$ \\
\hline 6 & 71 & $\mathrm{~F}$ & Alcohol & 73 & 12 & 8.5 & ERCP & $1.9 / 7.5$ \\
\hline 7 & 47 & M & Alcohol & 4 & 5 & - & $E S W L+E R C P$ & $2.3 / 9.4$ \\
\hline 8 & 52 & $\mathrm{~F}$ & Alcohol & 6 & 5 & 10 & $E S W L+E R C P$ & $1.7 / 8.3$ \\
\hline 9 & 59 & $M$ & Alcohol & 138 & 21 & - & $E S W L+E R C P$ & $1.6 / 9.7$ \\
\hline 10 & 47 & M & Alcohol & 11 & 4 & 8.5 & Absent of stone & $1.4 / 16.3$ \\
\hline
\end{tabular}

PS, plastic stent; ERCP, endoscopic retrograde cholangiopancreatography; ESWL, extracorporeal shock wave lithotripsy; MPD, main pancreatic duct.

\begin{tabular}{|c|c|c|c|c|c|c|c|c|c|}
\hline Case & $\begin{array}{l}\text { Type of } \\
\text { FCSEMS }\end{array}$ & $\begin{array}{l}\text { Diameter } \\
\text { and length } \\
\text { of FCSEMS } \\
(\mathrm{mm} / \mathrm{cm})\end{array}$ & $\begin{array}{l}\text { Early com- } \\
\text { plications }\end{array}$ & $\begin{array}{l}\text { Treatment } \\
\text { of early com- } \\
\text { plications }\end{array}$ & $\begin{array}{l}\text { Late } \\
\text { complications }\end{array}$ & $\begin{array}{l}\text { Treatment } \\
\text { of late com- } \\
\text { plications }\end{array}$ & $\begin{array}{l}\text { Duration } \\
\text { of stent- } \\
\text { ing (days) }\end{array}$ & $\begin{array}{l}\text { Improve- } \\
\text { ment in } \\
\text { stricture }\end{array}$ & $\begin{array}{l}\text { Stent-induced } \\
\text { stricture }\end{array}$ \\
\hline 1 & D-type & $8 / 6$ & $\begin{array}{l}\text { Intolerable } \\
\text { pain }\end{array}$ & $\begin{array}{l}\text { Removal of } \\
\text { FCSEMS }\end{array}$ & - & - & 7 & No & No \\
\hline 2 & D-type & $10 / 10$ & No & - & $\begin{array}{l}\text { Asymptomatic } \\
\text { distal migration }\end{array}$ & No & 18 & Yes & No \\
\hline 3 & $\begin{array}{l}\text { Bumpy- } \\
\text { type }\end{array}$ & $8 / 5$ & No & - & $\begin{array}{l}\text { Suppurative } \\
\text { pancreatic ductitis }\end{array}$ & $\begin{array}{l}\text { Removal of } \\
\text { FCSEMS + ENPD }\end{array}$ & 85 & Yes & No \\
\hline 4 & $\begin{array}{l}\text { Bumpy- } \\
\text { type }\end{array}$ & $8 / 6$ & No & - & $\begin{array}{l}\text { Suppurative } \\
\text { pancreatic ductitis }\end{array}$ & $\begin{array}{l}\text { Cleaning of } \\
\text { FCSEMS }\end{array}$ & 92 & Yes & Yes \\
\hline 5 & $\begin{array}{l}\text { Bumpy- } \\
\text { type }\end{array}$ & $8 / 7$ & No & - & No & - & 71 & Yes & No \\
\hline 6 & $\begin{array}{l}\text { Bumpy- } \\
\text { type }\end{array}$ & $8 / 5$ & $\begin{array}{l}\text { Intolerable } \\
\text { pain }\end{array}$ & Analgesics & $\begin{array}{l}\text { Asymptomatic } \\
\text { distal migration }\end{array}$ & $\begin{array}{l}\text { Replacement of } \\
\text { FCSEMS }\end{array}$ & 204 & Yes & Yes \\
\hline 7 & $\begin{array}{l}\text { Bumpy- } \\
\text { type }\end{array}$ & $8 / 7$ & $\begin{array}{l}\text { Intolerable } \\
\text { pain }\end{array}$ & Analgesics & No & - & 77 & Yes & No \\
\hline 8 & $\begin{array}{l}\text { Bumpy- } \\
\text { type }\end{array}$ & $8 / 6$ & No & - & No & - & 108 & Yes & No \\
\hline 9 & $\begin{array}{l}\text { Bumpy- } \\
\text { type }\end{array}$ & $8 / 7$ & No & - & No & - & 196 & Yes & No \\
\hline 10 & $\begin{array}{l}\text { Bumpy- } \\
\text { type }\end{array}$ & $8 / 7$ & Pancreatitis & $\begin{array}{l}\text { Removal of } \\
\text { FCSEMS }\end{array}$ & - & - & 2 & No & No \\
\hline
\end{tabular}

FCSEMS, fully covered self-expandable metal stent; ENPD, endoscopic naso-pancreatic drainage.

11.2.0 (SAS, Cary, NC, USA). A $P$ value $<0.05$ was considered statistically significant.

\section{Results}

$\nabla$

\section{Patient characteristics}

Ten patients ( 6 men and 4 women) with a median age of 50 years (IQR, 47 - 58 years) with refractory pancreatic duct strictures due to chronic pancreatitis were enrolled from November 2008 to August 2011 ( Table 1). The toxic or etiologic factors of their chronic pancreatitis were alcohol in nine patients, and trauma in one patient. Median duration from initial PS placement was 17 months (IQR, 6-75 months). The median number of previous ERCP procedures was 8.5 (IQR, 5-18). Seven patients had concomitant PSs in the bile duct for a biliary stricture secondary to chronic pancreatitis. Seven patients had calcified stones in the
MPD and underwent ESWL, endoscopic removal, or both prior to FCSEMS placement.

\section{Technical success of FCSEMS deployment and adverse} events with indwelling FCSEMS

FCSEMS ( $D$ type in 2 patients, Bumpy type in 8 patients) were successfully deployed in all patients. FCSEMSs were $8-10 \mathrm{~mm}$ in diameter and $5-10 \mathrm{~cm}$ in length ( Table 2 ). All FCSEMS were inserted via the major papilla, except in one case with insertion via the minor papilla.

Early complications were intolerable abdominal pain in 3 patients and pancreatitis in 1 patient, resulting in early stent removal in two patients (Case 1 and Case 10) within 1 week (Case 1 for severe pain and Case 10 for pancreatitis). Two of 3 patients with pain recovered with the use of analgesics only within a few days. One patient with pain (Case 1) was discharged once because the pain was tolerable, but he was re-admitted due to worsening pain 1 week after FCSEMS placement, necessitating FCSEMS removal. In 


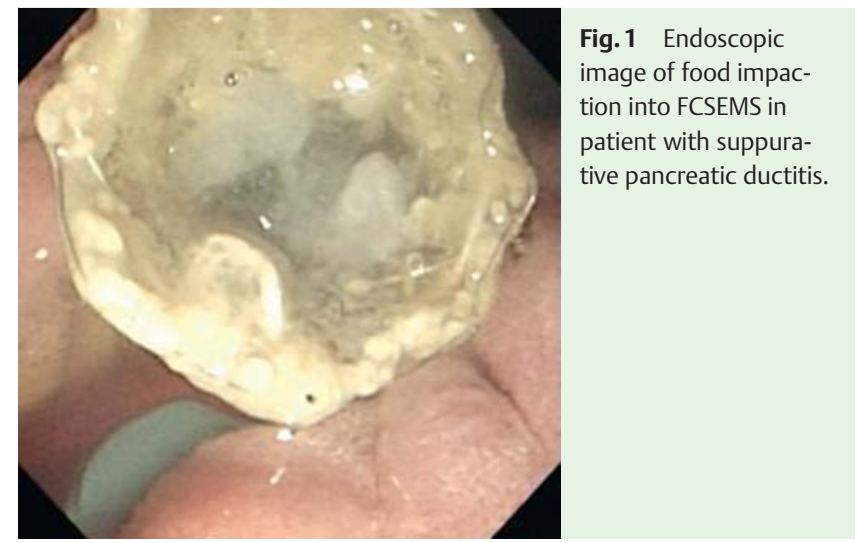

one patient with pancreatitis (Case 10), a CT scan showed that extrapancreatic inflammatory changes extended beyond the left inferior renal pole. These findings indicated severe acute pancreatitis according to Japanese criteria [23], and C-reactive protein and white blood cell counts increased to $16.4 \mathrm{mg} / \mathrm{dL}$ and $17200 / \mu \mathrm{L}$, respectively 2 days after the procedure. Therefore, the FCSEMS was removed for the patient's safety, and the pancreatitis improved with conservative management.

Late complications with an indwelling FCSEMS included asymptomatic distal migration and suppurative pancreatic ductitis. Asymptomatic distal migration occurred in two patients (Case 2 and Case 6). In the former case, with a D-type stent, the stent was found to have completely migrated from the pancreatic duct on the follow-up X-ray at day 18 . He did not require re-insertion of a FCSEMS because of resolution of pain, and improvement of the MPD stricture was confirmed by ERCP 3 months after placement. In the latter case, with a Bumpy-type stent, partial distal migration was revealed during ERCP for scheduled stent removal 3 months after placement. During stent placement, the stricture extended from the ampulla to near the corner of the WirsungSantorini junction, so that an FCSEMS $5 \mathrm{~cm}$ in length was placed just before the corner. Consequently, the proximal end of the stent did not sufficiently expand, and this led to slight distal migration of the stent. Because of insufficient improvement in the stricture, we placed a new FCSEMS, $6 \mathrm{~cm}$ in length, across the corner of the Wirsung-Santorini junction for an additional 3 months. Subsequently, the proximal end of the stent expanded sufficiently so that the stricture was improved at ERCP after 3 months, with no stent migration. Suppurative pancreatic ductitis occurred in 2 patients (Case 3 and Case 4 ) because of FCSEMS occlusion with foods at day 84 and day 49, respectively. Symptoms and signs in these patients were high-grade fever, shivering, and abdominal pain. The diagnosis was made with laboratory tests including raised white blood cell count and C-reactive protein, and endoscopic imaging of food impaction within the FCSEMS ( Fig. 1). In addition to the administration of antibiotics, removal of the FCSEMS and naso-pancreatic drainage tube placement were performed in Case 3 and cleaning of the lumen of the FCSEMS using an extraction balloon was performed in Case 4.

\section{Removal of FCSEMS and ERP findings immediately after removal}

All FCSEMS were easily removed using snare forceps without any complications. Median duration of stenting was 81 days (IQR, 15-130 days). ERP immediately after removal of FCSEMSs revealed definite improvements in the stricture in 8 patients
(Cases 2-9) ( $\bullet$ Fig.2). Median diameter of the narrowest portion of the stricture significantly increased from $1.8 \mathrm{~mm}$ (IQR, $1.6-2.4 \mathrm{~mm}$ ) to $3.2 \mathrm{~mm}$ (IQR, $2.9-3.7 \mathrm{~mm}$ ) after FCSEMS placement $(P=0.002)$. Stent-induced ductal strictures were found in two patients (Case 4 and Case 6 ) related to the proximal intraductal tip of the FCSEMSs ( Table 2 ). In Case 6, a stent-induced stricture was detected on ERCP at the time of removal of the second FCSEMS. Because patients were asymptomatic and the strictures were not so tight, no treatment was performed at that time.

\section{Recurrence and other adverse events after FCSEMS removal}

In 8 patients with 3 months placement of FCSEMS as per the schedule, recurrence of symptoms occurred in 5 patients (63\%) because of the following causes: relapse of the stricture in 2 (Case 3 and Case 7); stent-induced stricture in 1 (Case 4); impaction of MPD stones in 1 (Case 5); and development of a pseudocyst in 1 (Case 8 ) ( Table 3 ). Case 3 was admitted with acute pancreatitis at 84 days after stent removal and treated with reinsertion of an FCSEMS. Case 7 developed mild pain recurrence the day after stent removal, and only required analgesics. Case 4 was admitted with severe pain at 215 days after stent removal. ERCP revealed worsening of the stent-induced stricture, though no relapse of the original stricture, and multiple PSs were placed for stricture resolution. Cases 5 and 8 were treated with endoscopic removal of stones, and endoscopic ultrasound-guided pseudocyst drainage (EUS-PCD), respectively. Median recurrence-free survival was eight months in these eight patients (๑ Fig.3).

\section{Outcomes at the latest follow-up}

The last follow-up date of this study was September 30, 2013. In eight patients with three months placement of FCSEMS as per the schedule, the median follow-up period was 35 months (IQR, 2342 months). At the latest follow-up of the study period, seven of eight patients (Cases 2, 3, 5, 6, 7, 8, and 9) were free from stenting or surgery ( Fig.4). In these 7 patients, only 2 patients had mild abdominal pain requiring daily analgesics (Case 3 and Case 7). The remaining patient (Case 4), who was treated with multiple PSs for stent-induced strictures, underwent periodic replacement of multiple PSs, even at 42 months after SEMS removal.

Two patients with early stent removal had poor outcomes. In Case 1 , recurrence occurred at 90 days after stent removal due to unresolved stricture, and multiple PS placements were performed. However, stent-free status could not be achieved after 57 months follow-up. In case 10, the FCSEMS was removed because of pancreatitis at two days after placement, and he underwent naso-pancreatic drainage tube placement for treatment of pancreatitis. After improvement of pancreatitis, multiple PS placements were performed to dilate the stricture, but pancreatitis occurred again. Finally, he underwent pancreatoduodenectomy to resolve the stricture.

\section{Discussion \\ $\nabla$}

In the current study, recurrent pain occurred in $63 \%$ of patients with 3 months of FCSEMS placement. This result seems to be worse than those of previous studies ( $\bullet$ Table 4 ). The reasons are considered to be as follows: the longer follow-up duration compared to that in other studies and the inclusion of causes 

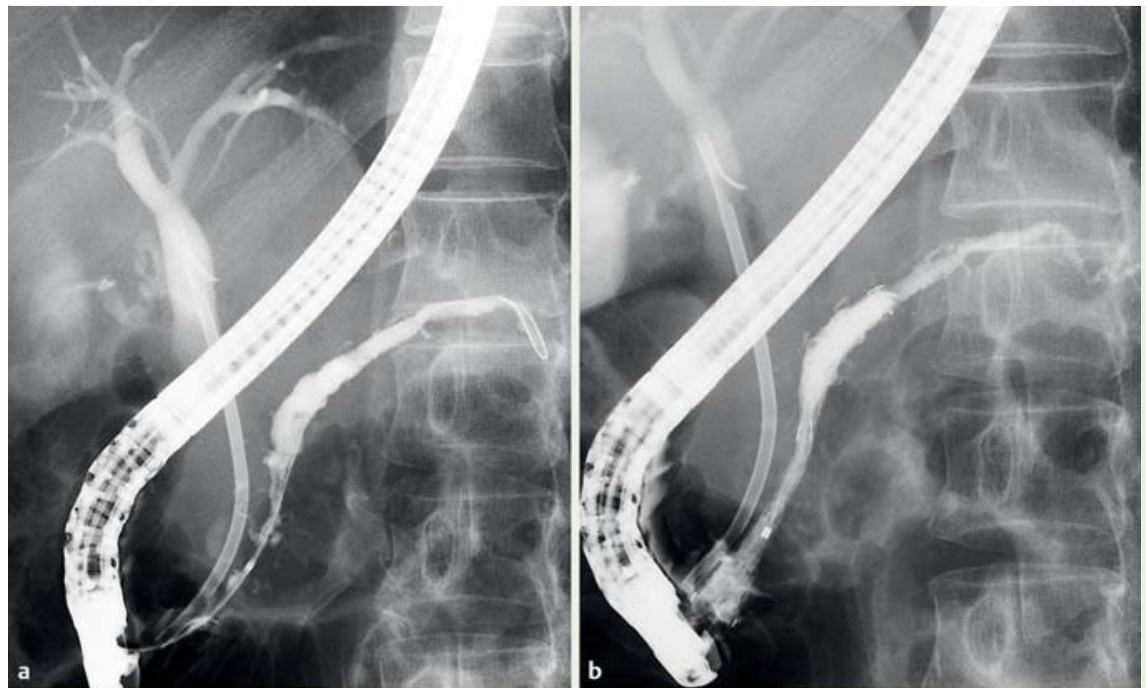

Fig. 2 Pancreatography before and after FCSEMS placement (Case 5). a Refractory main pancreatic duct stricture of the head portion of the pancreas was noted on the pancreatography. b A FCSEMS ( $8 \mathrm{~mm}$ in diameter, $7 \mathrm{~cm}$ in length) was placed for this stricture. $\mathbf{c}$ Just before the removal of the FCSEMS 3 months after placement. The FCSEMS was fully expanded. $\mathbf{d}$ Improvement of the stricture was shown on the balloon-occluded pancreatography just after removal of the FCSEMS.
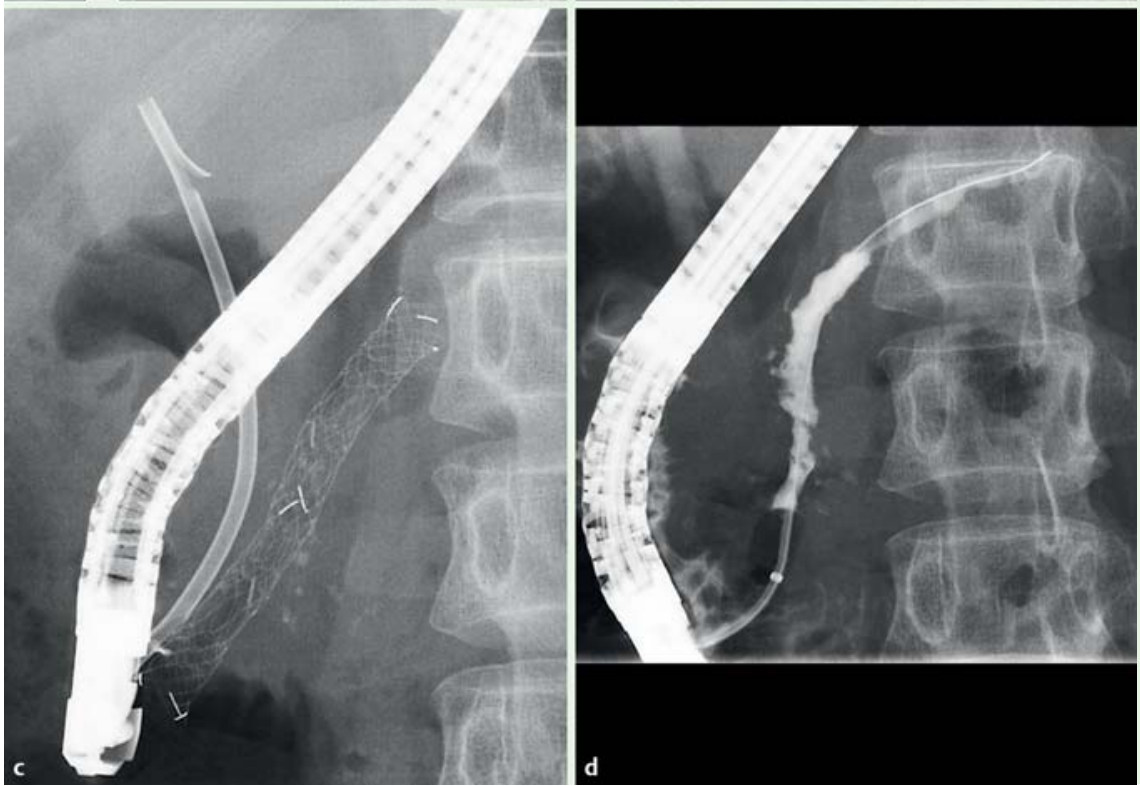

\begin{tabular}{|c|llll|} 
Case & $\begin{array}{l}\text { Follow-up } \\
\text { periods (months) }\end{array}$ & $\begin{array}{l}\text { Presence and days after } \\
\text { removal of pain recurrence }\end{array}$ & $\begin{array}{l}\text { Cause and treatment } \\
\text { of recurrence }\end{array}$ & $\begin{array}{l}\text { Status at latest } \\
\text { follow-up }\end{array}$ \\
\hline 1 & 57 & Yes, 90 & Unsolved stricture, multiple PSs & PS in situ \\
\hline 2 & 43 & No & - & No stent \\
\hline 3 & 42 & Yes, 84 & Recurrent stricture, FCSEMS & No stent \\
\hline 4 & 42 & Yes, 215 & Stent-induced stricture, multiple PSs & PS in situ \\
\hline 5 & 41 & Yes, 274 & MPD stones, Removal of stones & No stent \\
\hline 6 & 28 & No & - & No stent \\
\hline 7 & 26 & Yes, 1 & Recurrent stricture, conservative & No stent \\
\hline 8 & 22 & Yes, 81 & Pseudocyst, EUS-PCD & No stent \\
\hline 9 & 19 & No & - & No stent \\
\hline 10 & 23 & Yes, 0 & Unsolved stricture, multiple PSs & Surgery \\
\hline
\end{tabular}

Table 3 Outcomes after FCSEMS removal.

FCSEMS, fully covered self-expandable metal stent; MPD, main pancreatic duct; EUS-PCD, endoscopic ultrasound-guided pseudocyst drainage.

other than relapse of strictures, such as pancreatic duct stones or pseudocysts. When these causes were excluded, only 3 of 8 patients (38\%) developed recurrence of symptoms due to pancreatic duct strictures alone. This result is not satisfactory, but not substantially worse than those of previous studies, considering the longer follow-up duration.

The technical success rate of single PS placement for a benign pancreatic duct stricture was reported to be up to $90 \%$ [24], and pain relief was achieved in $74 \%-94 \%$ of patients after successful stent placement [3-6]. However, only $50 \%-70 \%$ of patients who respond to single PS placement can maintain this response after stent removal $[6-9,10]$. Costamagna et al. reported that temporary placement of multiple PSs for 6 to 12 months in refractory cases provided $89 \%$ persistent pain resolution during long-term follow-up after stent removal (mean, 38 months) [11]. However, in patients with severe strictures, deployment of multiple PSs is sometimes difficult, and stents should be replaced every 3 months. Placement of FCSEMSs may provide some advantages 


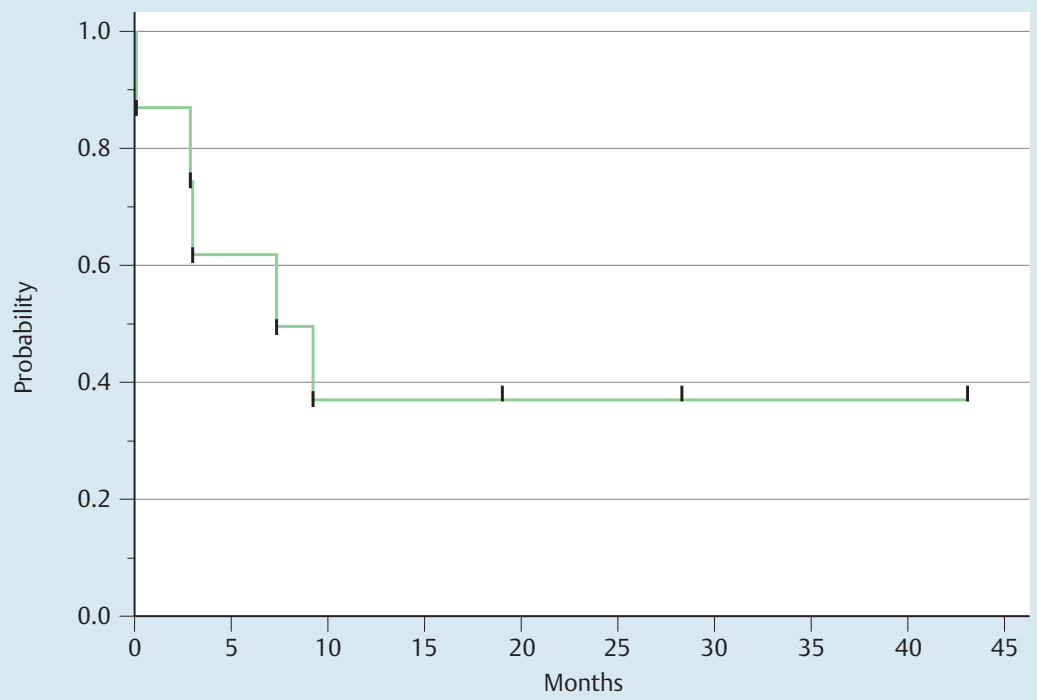

Fig. 3 Recurrence-free survival after removal of FCSEMS.

Number at risk

$8 \quad 5 \quad 1$

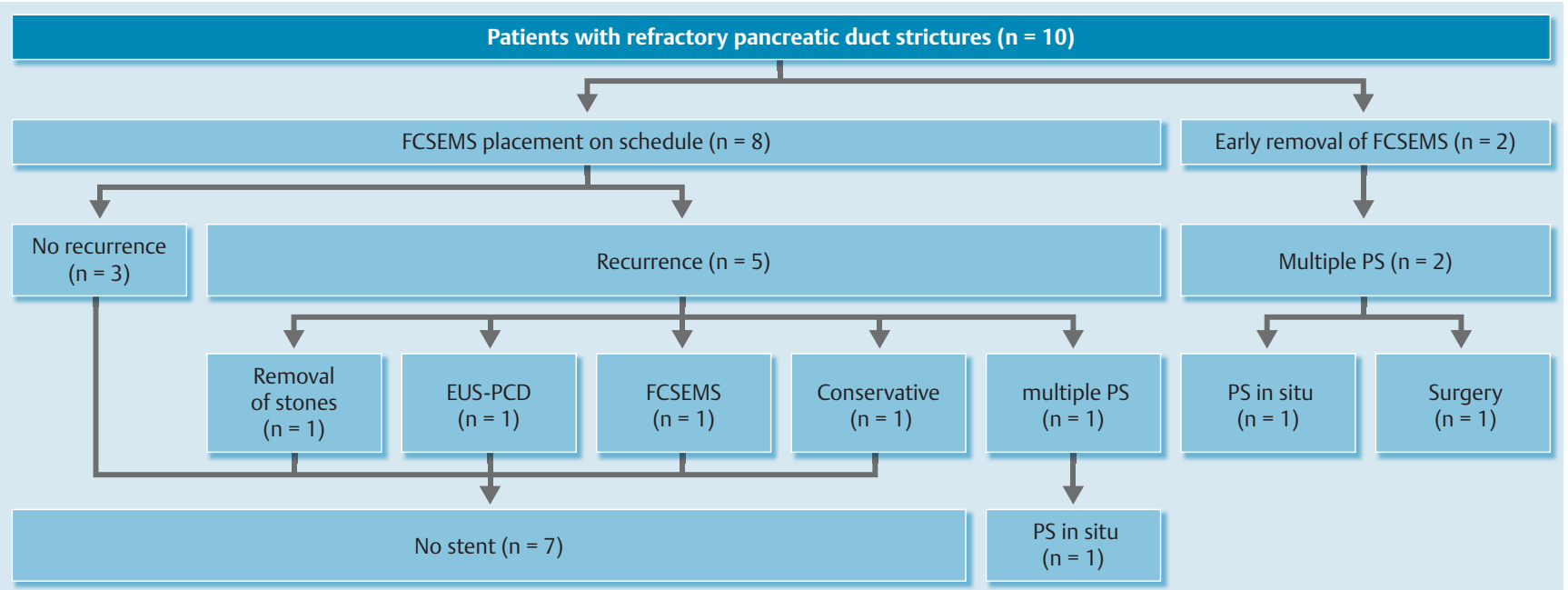

Fig. 4 Flowchart of the study outcome. FCSEMS, fully covered self-expandable metal stent; MPD, main pancreatic duct; EUS-PCD, endoscopic ultrasoundguided pseudocyst drainage; PS, plastic stent.

over multiple PSs, such as easier procedures, longer stent paten$\mathrm{cy}$, and smaller number of endoscopic procedures, which results in cost reduction. Therefore, we suggest that placement of an FCSEMS is suitable for the primary treatment of refractory pancreatic duct strictures due to chronic pancreatitis. For patients who are unfit for FCSEMS placement because of stent-related pain or pancreatitis, placement of multiple PSs should be considered.

Optimal indwelling time of an FCSEMS for persistent resolution of a stricture is still not well known because information about the long-term outcomes of temporary FCSEMS placement is lacking. We conducted the present study in the middle of 2008. There were only 3 articles published regarding FCSEMS for pancreatic duct stricture secondary to chronic pancreatitis at that time [14-16]. The reasons we selected 3 months placement were as follows: first, the period of stenting in these previous articles was less than 3 months; second, relatively good outcomes were achieved in these articles; and third, it was not known if FCSEMS placed for over 3 months could be removed safely. Even though the longer indwelling time of an FCSEMS may provide a better outcome, Giacino et al. reported that two stents placed for 6 and 9 months were embedded in the pancreatic duct due to breakage of the covering membranes of the FCSEMS with tissue hyperplasia of the pancreatic duct, resulting in difficulty removing the FCSEMS [18]. On the other hand, Tringali et al. reported that FCSEMS were easily removed in 15 patients with 6 months placement [19]. Although removability and power of stricture resolution may depend on the type of FCSEMS, 3 months placement of an FCSEMS may be safe for removal but insufficient for stricture resolution, while 6 months placement has a potential risk of being un-removable. Therefore, the optimal stenting duration is considered to be 5 to 6 months.

Two patients required early removal of FCSEMS for intolerable pain or pancreatitis in the present study. Intolerable pain occurred in three patients, however, only one needed stent removal. Pain after FCSEMS placement was reported in 0\% [15-17] to $30 \%[14,18]$ in previous studies. In previous studies, FCSEMS with 8 or $10 \mathrm{~mm}$ diameter were placed for cases with pain. We 
Table 4 Data from previous studies and the current study regarding FCSEMS for pancreatic duct stricture in chronic pancreatitis.

\begin{tabular}{|c|c|c|c|c|c|c|c|c|c|c|}
\hline Author & Year & Indication & N & Type of FCSEMS & $\begin{array}{l}\text { Diameter } \\
\text { and length } \\
\text { of FCSEMS } \\
(\mathrm{mm} / \mathrm{cm})\end{array}$ & $\begin{array}{l}\text { Planned } \\
\text { duration } \\
\text { of stent- } \\
\text { ing }\end{array}$ & $\begin{array}{l}\text { Migration } \\
\text { rate (\%) }\end{array}$ & $\begin{array}{l}\text { Rate of stent- } \\
\text { induced stric- } \\
\text { ture (\%) }\end{array}$ & $\begin{array}{l}\text { Recurrence } \\
\text { rate of } \\
\text { symptoms } \\
\text { after stent } \\
\text { removal (\%) }\end{array}$ & $\begin{array}{l}\text { Median } \\
\text { follow-up } \\
\text { period } \\
\text { (months) }\end{array}$ \\
\hline $\begin{array}{l}\text { Okushima K, } \\
\text { et al. [14] }\end{array}$ & 2005 & $\begin{array}{l}\text { Symptomatic } \\
\text { stricture }\end{array}$ & 3 & Diamond & $8,10 / \mathrm{N} / \mathrm{A}$ & $3-7$ days & 0 & 0 & 0 & $22^{1}$ \\
\hline $\begin{array}{l}\text { Sauer B, } \\
\text { et al. [15] }\end{array}$ & 2008 & $\begin{array}{l}\text { Refractory } \\
\text { for PS }\end{array}$ & 6 & VIABIL & $8,10 / \mathrm{N} / \mathrm{A}$ & 3 months & 0 & 0 & 60 & $8^{2}$ \\
\hline $\begin{array}{l}\text { Park do H, } \\
\text { et al. [16] }\end{array}$ & 2008 & $\begin{array}{l}\text { Refractory } \\
\text { for PS }\end{array}$ & 13 & Niti-S D type & $6,8 / 5,6,7$ & 2 months & 39 & 0 & 0 & 5 \\
\hline $\begin{array}{l}\text { Moon SH, } \\
\text { et al. [17] }\end{array}$ & 2010 & $\begin{array}{l}\text { Refractory } \\
\text { for PS }\end{array}$ & 32 & $\begin{array}{l}\text { Niti-S Bumpy } \\
\text { type }\end{array}$ & $\begin{array}{l}6,8,10 / 4 \\
5,6,7,8\end{array}$ & 3 months & 0 & 16 & 10 & $5^{1}$ \\
\hline $\begin{array}{l}\text { Giacino C, } \\
\text { et al. [18] }\end{array}$ & 2012 & $\begin{array}{l}\text { Symptomatic } \\
\text { stricture }\end{array}$ & 10 & $\begin{array}{l}\text { WallFlex/Wall- } \\
\text { Stent }\end{array}$ & $8,10 / 4,6,8$ & 5 months & 0 & N/A & 40 & $20^{1}$ \\
\hline $\begin{array}{l}\text { Tringali A, } \\
\text { et al. [19] }\end{array}$ & 2015 & $\begin{array}{l}\text { Refractory } \\
\text { for PS }\end{array}$ & 15 & $\begin{array}{l}\text { Niti-S Bumpy } \\
\text { type }\end{array}$ & $6,8 / 3,4,5$ & 6 months & 47 & 27 & 43 & 12 \\
\hline $\begin{array}{l}\text { Current } \\
\text { study }\end{array}$ & & $\begin{array}{l}\text { Refractory } \\
\text { for PS }\end{array}$ & 10 & $\begin{array}{l}\text { Niti-S D/Bumpy } \\
\text { type }\end{array}$ & $\begin{array}{l}8,10 / 5,6 \\
7,10\end{array}$ & 3 months & 20 & 20 & 63 & 35 \\
\hline
\end{tabular}

PS, plastic stent; NS, not applicable.

1 mean

2 maximum

chose stents with the biggest diameter to match the MPD diameter upstream of the stricture in order to create a definite dilation of the stricture, and, consequently, only $8-\mathrm{mm}$ or $10-\mathrm{mm}$ stents were used in the present study. FCSEMS of $6 \mathrm{~mm}$ diameter might prevent post-procedure abdominal pain. Basically, pain will spontaneously improve without stent removal after FCSEMS expansion [18]. However, in the present study, the patient who required stent removal suffered from severe pain even after 1 week of placement. The diameter of the upstream pancreatic duct of the stricture before SEMS placement was $8 \mathrm{~mm}$, and we correctly used the 8-mm diameter stent. This patient had depression and he took daily antidepressants, so the degree of his pain could have been influenced by his mental status. In previous studies, some patients have suffered from pancreatitis after FCSEMS placement $[16,17]$, but there were no cases requiring stent removal unlike in the present study. In the patient with pancreatitis in our study, the pancreatic parenchyma was not so atrophic on the previous CT. This indicated preservation of pancreatic exocrine function, and this should be considered a risk for procedure-related pancreatitis. Therefore, we chose a slimmer SEMS than recommended, according to upstream MPD diameter, to avoid pancreatitis. Nevertheless, pancreatitis still occurred. We think those patients who are unfit for FCSEMS should be considered as suitable for multiple PS placement.

In previous studies, migration did not occur with the VIABIL stent [15] or WallFlex stent, [18] but did occur in 39\% of patients with a Niti-S D-type stent [16], and 0 to $47 \%$ with a Niti-S Bumpy-type stent $[17,19]$. We previously reported that the low radial force of the FCSEMS for malignant biliary obstruction was a risk factor for migration [25]. This principle may be applicable to the MPD. An FCSEMS with relatively high radial force (VIABIL stent and WallFlex stent) showed no migration, while the Niti-S series showed a high migration rate. The Bumpy-type stent was developed to prevent migration, and actually, migration did not occur in 32 patients in the first report [17]. However, $47 \%$ of patients had complete migration in the second report [19]. This difference may be related to stent length: shorter stents $(3 \mathrm{~cm}$ to $5 \mathrm{~cm})$ were used in the second report compared to those used in the first report ( $4 \mathrm{~cm}$ to $8 \mathrm{~cm}$ ). It is controversial whether the anti-migration system of the Bumpy-type stent is useful. In the present study, distal migration occurred in two patients with a Niti-S stent (one in a D-type stent, and the other in a Bumpy-type stent) without symptoms. In the case with a D-type stent, the stent had completely migrated within 18 days in spite of being a wide and long FCSEMS $(10 \mathrm{~mm} / 10 \mathrm{~cm}$, respectively). A diameter of $3.2 \mathrm{~mm}$ for the residual stricture before placement of FCSEMS was not so bad; it is exactly the same as the median diameter of the narrowest portion of the stricture obtained 3 months after placement of FCSEMS. Therefore, we cannot exclude that a satisfactory calibration obtained by previous plastic stenting could be at least partly involved in the early spontaneous migration of the FCSEMS, in addition to the stent property by itself. In the case with a Bumpy-type stent, we could avoid migration in future by using a longer stent. Full expansion of the proximal end of the FCSEMS is considered to be important in preventing distal migration.

Stent-induced ductal strictures occurred in two patients in the present study. In one patient, symptoms occurred at 7 months after removal, and multiple PS placement was ongoing at the latest follow-up. Stent-induced strictures were reported in two previous studies $[17,19]$. In these studies and the current study, all stent-induced strictures occurred with the Bumpy-type stent. The proximal, flared end of the Bumpy-type stent may cause structuring.

Contrary to concerns, pancreatic ductitis has never been reported in previous studies in relation to FCSEMS in the MPD. However, suppurative pancreatic ductitis developed in 2 patients due to food impaction in the FCSEMS in the present study. There was no duodenal stenosis in these patients, so it was unclear why food impaction occurred only in these patients. To prevent food impaction, an anti-reflux metal stent, as used in biliary strictures, may be a useful option [26].

There are some limitations in the present study. First, this pilot study involved a small sample size with no comparison arm. Second, the type of FCSEMS used in this study was not unified. Third, only refractory cases were enrolled, and the efficacy of initial placement of the FCSEMS for pancreatic duct strictures was not 
evaluated. Fourth, there was no defined strategy after failed placement of the FCSEMS. Finally, there was no objective evaluation criteria for recurrent pain, such as the Izbicki scoring system [27].

In conclusion, placement of an FCSEMS appears to be a feasible and potentially effective option for the management of refractory pancreatic duct strictures due to chronic pancreatitis during long-term follow-up. The optimal duration of stenting, and the adequate type and size of FCSEMS have not as yet been elucidated. Adverse events occurred in $70 \%$ of patients in total, and stent-induced ductal changes, stent migration and ductitis remain as major issues to be solved. Further investigation is needed to resolve these problems.

\section{Competing interests: None}

\section{References}

1 Huibregtse K, Schneider B, Vrij A et al. Endoscopic pancreatic drainage in chronic pancreatitis. Gastrointest Endosc 1988; 34: 9-15

2 Gabbrielli A, Pandolfi M, Mutignani $M$ et al. Efficacy of main pancreaticduct endoscopic drainage in patients with chronic pancreatitis, continuous pain, and dilated duct. Gastrointest Endosc 2005; 61: 576-581

3 Cremer $M$, Deviere J, Delhaye $M$ et al. Stenting in severe chronic pancreatitis: results of medium-term follow-up in seventy-six patients. Endoscopy 1991; 23: 171-176

4 Smits ME, Badiga SM, Rauws EA et al. Long-term results of pancreatic stents in chronic pancreatitis. Gastrointest Endosc 1995; 42: 461 - 467

5 Binmoeller KF, Jue P, Seifert $H$ et al. Endoscopic pancreatic stent drainage in chronic pancreatitis and a dominant stricture: Long-term results. Endoscopy 1995; 27: 638 - 644

6 Ponchon T, Bory RM, Hedelius F et al. Endoscopic Stenting for Pain Relief in Chronic-Pancreatitis - Results of a Standardized Protocol. Gastrointest Endosc 1995; 42: 452 - 456

7 Rosch T, Daniel S, Scholz M et al. Endoscopic treatment of chronic pancreatitis: a multicenter study of 1000 patients with long-term followup. Endoscopy 2002; 34: 765 - 771

8 Delhaye $M$, Arvanitakis $M$, Verset $G$ et al. Long-term clinical outcome after endoscopic pancreatic ductal drainage for patients with painful chronic pancreatitis. Clin Gastroenterol Hepatol 2004; 2: 1096-1106

9 Eleftherladis $N$, Dinu F, Delhaye $M$ et al. Long-term outcome after pancreatic stenting in severe chronic pancreatitis. Endoscopy 2005; 37: $223-230$

10 Weber A, Schneider J, Neu B et al. Endoscopic stent therapy for patients with chronic pancreatitis: results from a prospective follow-up study. Pancreas 2007; 34: 287-294

11 Costamagna G, Bulajic M, Tringali A et al. Multiple stenting of refractory pancreatic duct strictures in severe chronic pancreatitis: long-term results. Endoscopy 2006; 38: $254-259$
12 Deviere J, Nageshwar ReddyD, Puspok A et al. Successful management of benign biliary strictures with fully covered self-expanding metal stents. Gastroenterology 2014; 147: 385-395

13 Eisendrath $P$, Devière J. Expandable metal stents for benign pancreatic duct obstruction. Gastrointest Endosc Clin N Am 1999; 9: 547-554

14 Okushima K, Yoshino J, Inui K et al. Short-term metal stenting for treatment of main pancrteatic duct strictures associated with chorinic pancreatitis. Dig Endosc 2005; 17: 230-234

15 Sauer B, Talreja J, Ellen K et al. Temporary placement of a fully covered self-expandable metal stent in the pancreatic duct for management of symptomatic refractory chronic pancreatitis: preliminary data (with videos). Gastrointest Endosc 2008; 68: 1173-1178

16 Park doH, Kim MH, Moon SH et al. Feasibility and safety of placement of a newly designed, fully covered self-expandable metal stent for refractory benign pancreatic ductal strictures: a pilot study (with video). Gastrointest Endosc 2008; 68: 1182 - 1189

17 Moon SH, Kim MH, Park doH et al. Modified fully covered self-expandable metal stents with antimigration features for benign pancreaticduct strictures in advanced chronic pancreatitis, with a focus on the safety profile and reducing migration. Gastrointest Endosc 2010; 72: $86-91$

18 Giacino C, Grandval P, Laugier R. Fully covered self-expanding metal stents for refractory pancreatic duct strictures in chronic pancreatitis. Endoscopy 2012; 44: 874-877

19 Tringali A, Familiari P, Barbaro $F$ et al. Fully covered self-expandable matal stents to dilate pancreatic duct strictures due to chronic pancreatitis: a pilot study. United European Gastroenterol J 2015; 3: A205

20 Dumonceau JM, Delhaye M, Tringali A et al. Endoscopic treatment of chronic pancreatitis: European Society of Gastrointestinal Endoscopy (ESGE) Clinical Guideline. Endoscopy 2012; 44: 784-800

21 Committee ASoP, Chandrasekhara V, Chathadi $K V$ et al. The role of endoscopy in benign pancreatic disease. Gastrointest Endosc 2015; 82: $203-214$

22 Nakai Y, Isayama $\mathrm{H}$, Togawa $\mathrm{O}$ et al. New method of covered wallstents for distal malignant biliary obstruction to reduce early stent-related complications based on characteristics. Dig Endosc 2011; 23: 49-55

23 Otsuki M, Takeda K, Matsuno $S$ et al. Criteria for the diagnosis and severity stratification of acute pancreatitis. World J Gastroenterol 2013; 19: $5798-5805$

24 Grimm H, Meyer WH, Nam VC et al. New modalities for treating chronic pancreatitis. Endoscopy 1989; $21: 70-74$

25 Nakai $Y$, Isayama $H$, Kogure $H$ et al. Risk factors for covered metallic stent migration in patients with distal malignant biliary obstruction due to pancreatic cancer. J Gastroenterol Hepatol 2014; 29: 1744 1749

26 Hamada T, Isayama $\mathrm{H}$, Nakai $\mathrm{Y}$ et al. Novel antireflux covered metal stent for recurrent occlusion of biliary metal stents: a pilot study. Dig Endosc 2014; 26: $264-269$

27 Cahen DL, Gouma DJ, Nio Yet al. Endoscopic versus Surgical Drainage of the Pancreatic Duct in Chronic Pancreatitis. N Engl J Med 2007; 356: $676-684$

Correction

Saburo Matsubara, Naoki Sasahira, Hiroyuki Isayama et al. Prospective pilot study of fully covered self-expandable metal stents for refractory benign pancreatic duct strictures: long-term outcomes Endoscopy International Open 2016, 04: 1215-1222 Abstract was missing and is added now. 